\title{
THERMAL INSULATION PERFORMANCE OF WOOD-PLASTIC COMPOSITE PANELS AS ALTERNATIVE TO ALUCOBOND CLADDING SHEETS FOR BUILDINGS
}

${ }^{*}$ Hadeel Mahmood Mussa ${ }^{1}$

1) College of Engineering, Mustansiriyah University, Baghdad, Iraq

2) College of Engineering, Mustansiriyah University, Baghdad, Iraq

\author{
Tawfeeq Wasmi M. Salih²
}

\begin{abstract}
Alucobond cladding sheets can be replaced by composite materials made of wood and plastic due to many desirable features such as high thermal resistance, high UV resistance, and sufficient mechanical properties besides their environmental and economic advantages. In this study, the thermal performance of wood-plastic composites made of pine wood and high-density polyethylene plastic are compared to plastic materials that used in the core of Alucobond sheets for building cladding. The specimens that manufactured during the experimental work had many combinations and the thermal conductivity coefficient has been measured in the laboratory. The results show that the thermal conductivity of the wood-plastic composites can be decreased about $25 \%$ by adding $30 \%$ wood content because k-value of wood is less than that of plastic. The cooling load for a typical building that used these panels has been expected using a local computer application, where the energy saving may reach to $35 \%$ during the summer time
\end{abstract}

Keywords: Thermal insulation, wood, plastic, composite materials, Alucobond sheets

\section{Introduction}

Alucobond is a light material consists of a plastic core, usually made of polyethylene, and covered by a layer of aluminum. It comes as sheets of different shapes, sizes and thicknesses. These kinds of sheets are widely used for facade cladding and roof edges in the modern buildings, as shown in Figure 1.

Beside that Alucobond cladding gives adequate appearance to the building, its main function is the energy saving specially in hot climates by reducing the heat transmitted inside due to reflected radiation from aluminum surface, as well as the heat conduction resistance by core plastic material.

Alucobond sheet still have some issues due to the high rate of consuming plastic sources, as well as the relatively high thermal conductivity of plastic comparing to other thermal insulation materials. These two problems have been subjects of interest for many researches.

Recently, many investigations have been developed to invest the sources of natural materials or recycled materials. Wood plastic composites (WPCs) are environmentally friend materials, where they can be manufactured from recycled plastics and waste woods [1].

The involving of wood in the production of plastic leads to enhance its thermo-physical properties, mechanical properties and also the advantages of low cost since they are wastes materials [2]. 
Several promising studies [3-19] have taken place in the evaluation of thermal properties of wood plastic composites (WPCs), for several wood types, wood contents, and polymer types as well as additives contents. Most of the studies were experimental investigations, while some others were theoretical and numerical studies or models.

The present study suggested WPCs made of two types of thermoplastics, high density polyethylene (HDPE) or polypropylene (PP) combined with pine wood flour in different concentrations $(10,20$ or $30 \%)$. These panels are used as alternative to conventional Alucobond panels which contain plastics in the core.
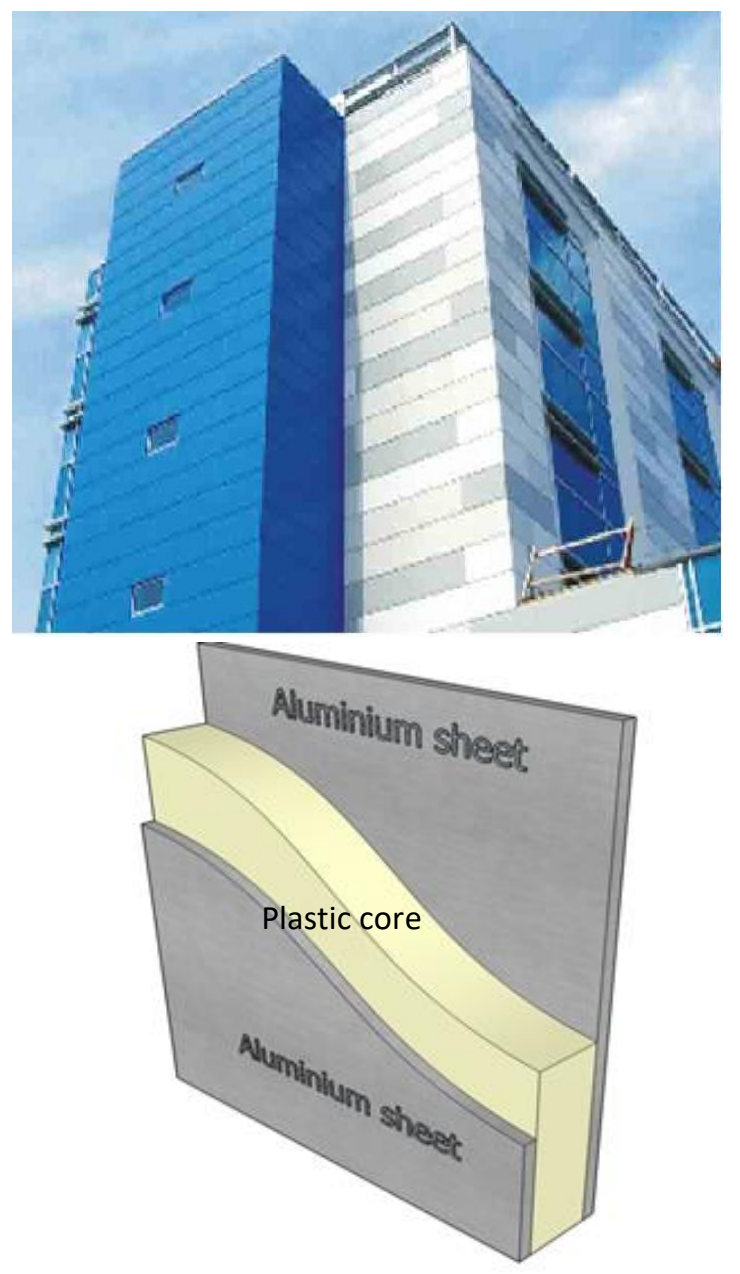

Figure 1. Alucobond cladding

\section{Experimental Work}

In the current study, composite materials made of recycled wood and plastic, known as woodplastic composites (WPCs), have proposed as thermal insulation panels in place of Alucobond sheets.

For this purpose, an experimental work has been done to manufacture and evaluate the thermal performance of WPCs. The work includes collecting raw materials of: pine wood, highdensity polyethylene (HDPE) and polypropylene (PP), as shown in Figure 2.

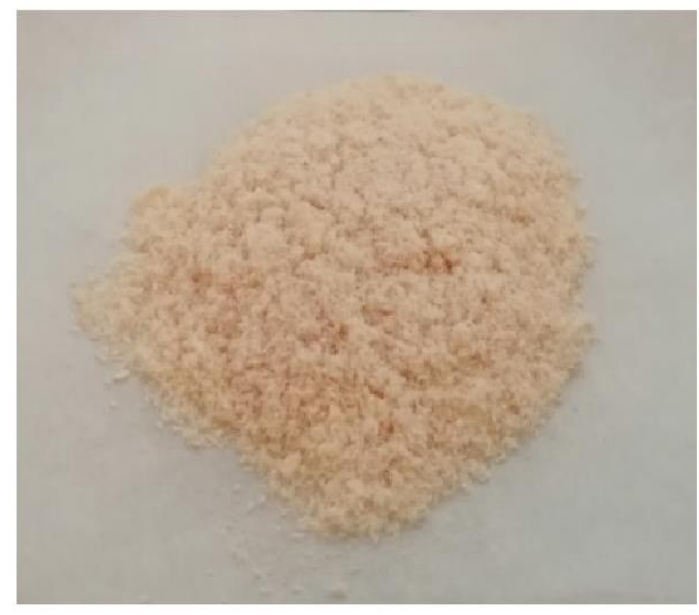

a. Wood flour

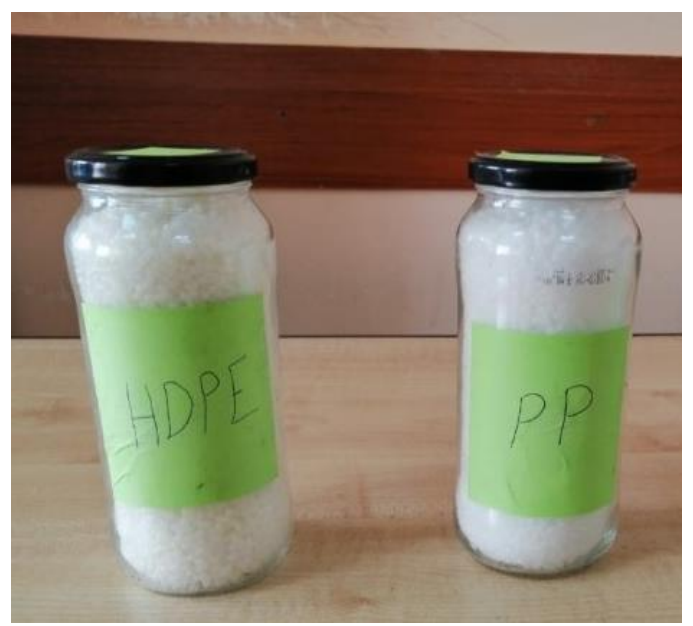

b. Plastics

Figure 2. Materials used in the study 
Then, a set of specimens with different wood concentrations and thicknesses have manufactured. Later, tests are done to measure the coefficient of thermal conductivity for the manufactured specimens.

The values of density for the selected materials are measured using common mass-dimension method. There is a slight percentage of variation (less than 10\%) with values from several sources, as shown in Table 1 . This variation is almost due to the difference in the feature of the materials.

The experimental work has done at Chemical Lab in Materials Engineering Department, Mustansiriyah University. Several devices and instruments have been used like, oven, thermometer, weight scale and mold. Some tools and auxiliaries have been used as well. The majority of WPC researches suggested considering an amount of wood less than that of plastic to ensure sufficient bonding between the two components, thus the current study assumed a wood content not exceeded $30 \%$ of the total weight. The wood was oven dried at $80{ }^{\circ} \mathrm{C}$ for 2 hours before processing to remove the moisture content (less than 5\%). However, WPC specimens prepared in the current study with their mixing ratios are shown in Table 2.

Table 1. Density of selected materials

\begin{tabular}{lccc}
\hline \multicolumn{1}{c}{ Material } & $\begin{array}{c}\text { Density } \\
\left(\mathrm{g} / \mathrm{cm}^{3}\right) \\
\text { measured }\end{array}$ & $\begin{array}{c}\text { Density } \\
\left(\mathrm{g} / \mathrm{cm}^{3}\right) \\
\text { referenced }\end{array}$ & $\begin{array}{c}\% \\
\text { Variation }\end{array}$ \\
$\begin{array}{l}\text { Pine wood } \\
(\mathrm{PW})\end{array}$ & 0.41 & $0.45[20-24]$ & $9 \%$ \\
$\begin{array}{l}\text { High density } \\
\text { polyethylene } \\
\text { (HDPE) }\end{array}$ & 0.97 & $0.95[25-27]$ & $2 \%$ \\
$\begin{array}{l}\text { Polypropylene } \\
\text { (PP) }\end{array}$ & 0.93 & $0.90[25-27]$ & $3 \%$ \\
\hline
\end{tabular}

Table 2. Mixing ratios of specimens used in the study

\begin{tabular}{lccc}
\hline WPC type & Mixing ratio (\%) & $\begin{array}{c}\text { No. of } \\
\text { specimens }\end{array}$ & $\begin{array}{c}\text { Thickness } \\
\text { mm }\end{array}$ \\
HDPE & 100 & 3 & $4,6,8$ \\
HDPE-PW & $90-10,80-20,70-30$ & 9 & $4,6,8$ \\
PP & 100 & 3 & $4,6,8$ \\
PP-PW & $90-10,80-20,70-30$ & 9 & $4,6,8$ \\
\hline
\end{tabular}

The desired quantities for each specimen components have weighted and combined in well mixing procedure, where two stages have proposed to ensure homogenous product as much as possible. In the first stage, some of the wood flour has mixed with the plastic grains in a bowl and then pour the mixture into a sheet of parchment paper to insert it easily to the oven for a period of time till the melting point. After that, the second stage of mixing is beginning by spreading the rest of the wood flour into the melted plastic and rolling it carefully. The oven used in the study is assigned for polymer meltworks which has the brand Jrad, with Italian thermostat operates up to $250{ }^{\circ} \mathrm{C}$, as shown in Figure 3.

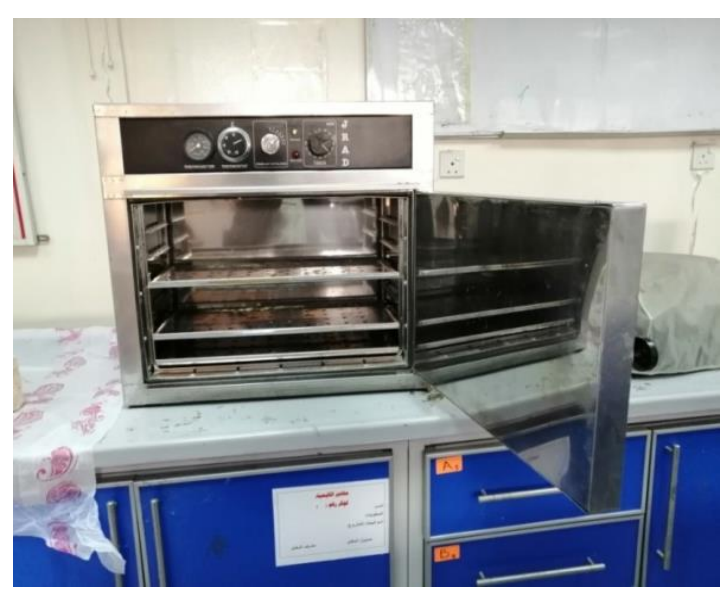

Figure 3. Oven used in the study 
The period that the plastic grains spent in the oven to get melting, starting from room temperature, was ranged between 20-30 minutes at a constant rate of heat $\left(10^{\circ} \mathrm{C} / \mathrm{min}\right)$. After that, the molten plastic-wood paste has ejected from the oven and inserted into the mold which has a square shape of $5 \mathrm{~cm}$ length, as shown in Figure 4. The paste of wood-plastic should be pressed in the mold. Finally, the specimens should be exposed to the still air for a period of 5 minutes for cooling.

The measurements of thermal conductivity values have conducted at the laboratory using MED-103 thermal conductivity apparatus, as shown in Figure 5. The test was done according to the standard ASTM C177 (Direct absolute technique), where the specimens have square shapes of $25 \mathrm{~cm}^{2}$ area with different thicknesses (4, 6 and $8 \mathrm{~mm}$ ), as shown in Figure 6. The device consists of a chamber and a thermometer. The chamber has an electric heater with a controlling source of heat, and there are two thermal sensors of type-k used should be placed between the hot and cold surfaces of the specimen. The chamber has sufficient thermal insulation. The electric circuit was switched on until the equilibrium condition is reached. The thermometer recorded until certain period of time till the steady-state.

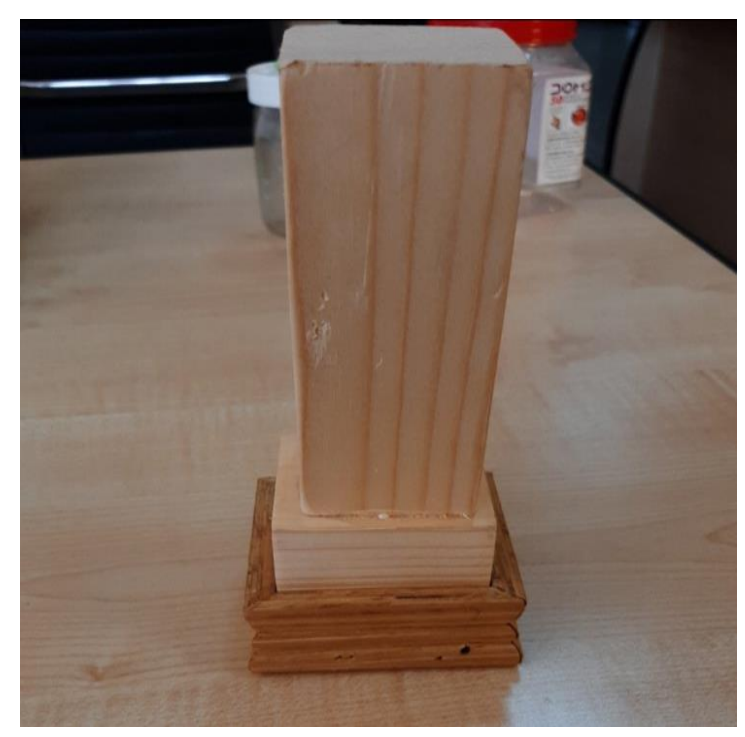

Figure 4. Mold used in the study

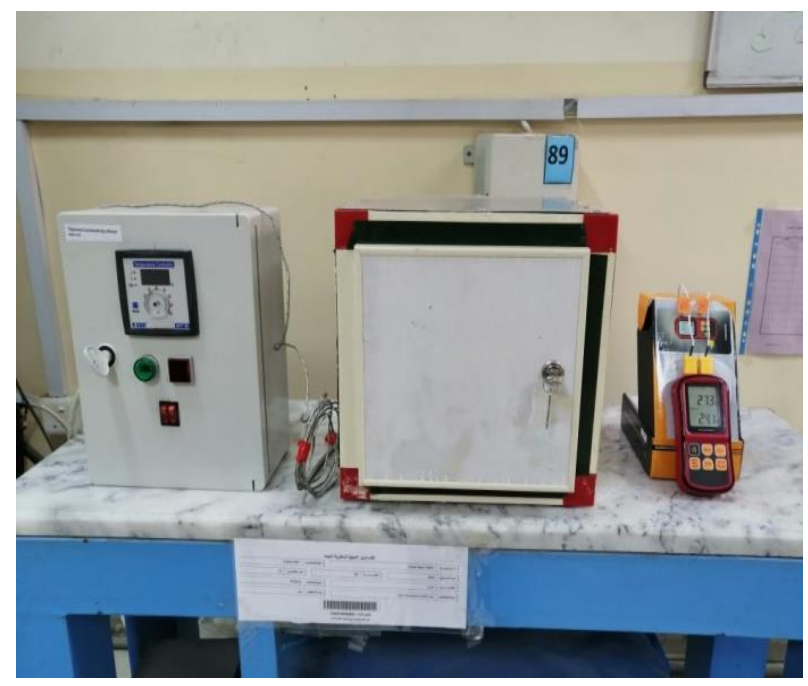

Figure 5. Apparatus used to measure thermal conductivity 


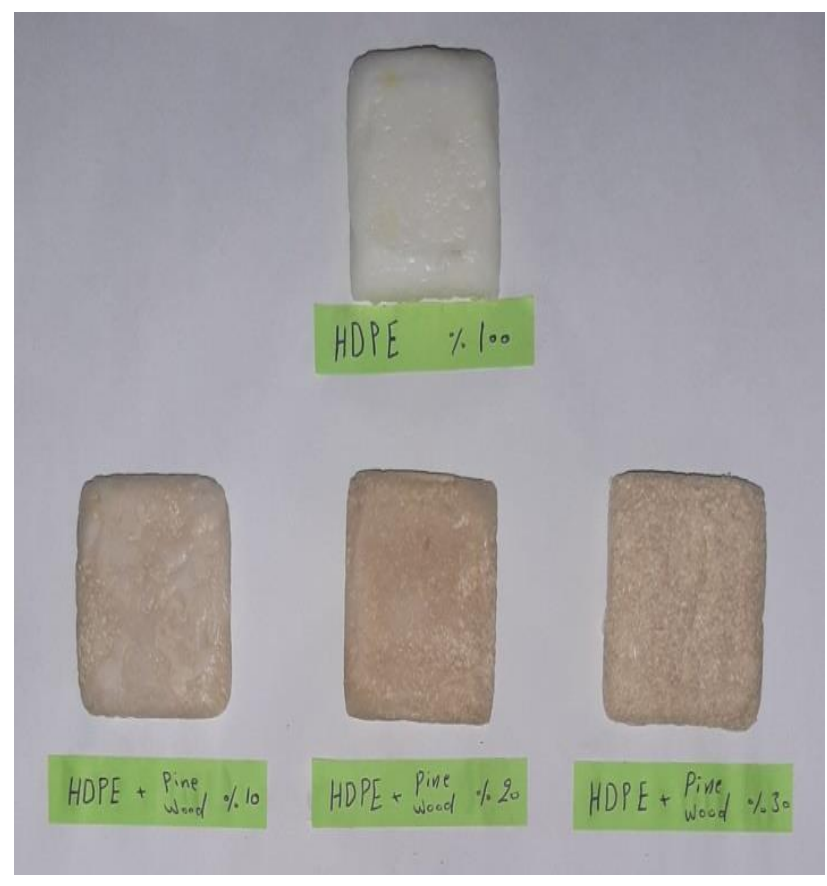

a. HDPE-PW specimens

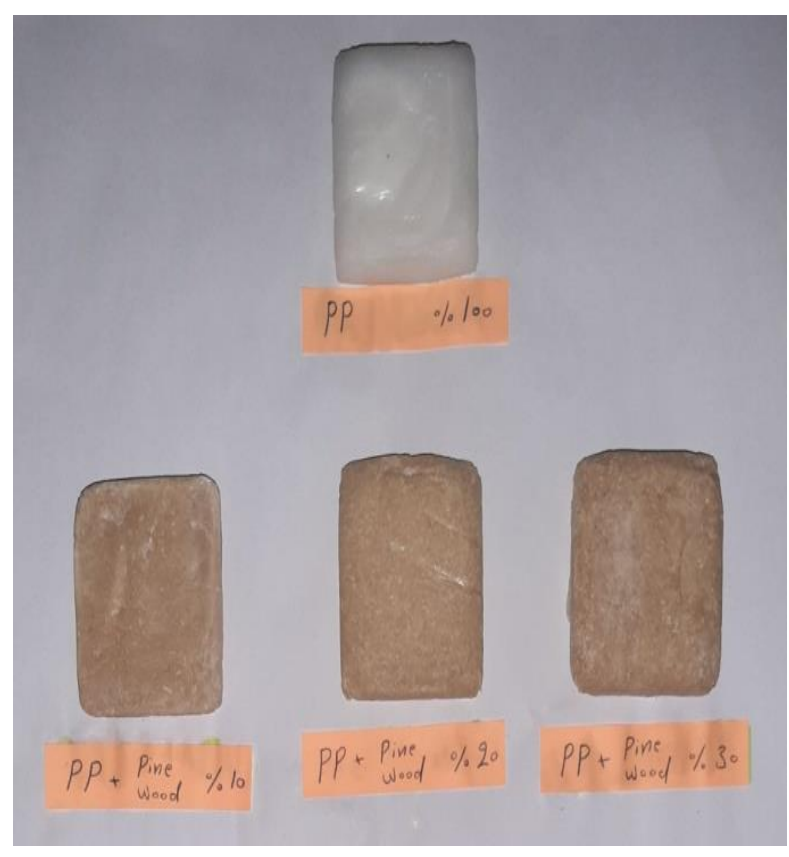

b. PP-PW specimens

Figure 6. Manufactured specimens

\section{Results and Discussions}

Evaluating the thermal performance of WPC insulating panels depends mainly on the values of thermal conductivity as an essential parameter in the thermal analysis.

The thermal conductivity ( $\mathrm{k}$-value) is the property which indicates whether the material is a good insulator or not. The values of thermal conductivity of WPCs have been compared with Alucobond core material which is considered as HDPE only. The set of results is classified into two groups: the effect of wood content on thermal conductivity, the effect of thickness, as shown in Figures 7 and 8.

In general, the increasing in the wood content leads to a reduction in $\mathrm{k}$-value for WPC material because $\mathrm{k}$-value of wood is less than that of polymer, thus the overall $\mathrm{k}$-value of the composite tends to decrease. This decreasing is appeared to be linear. For HDPE-wood composites, it is noticed that there is a significant reduction in $\mathrm{k}$-value (about $8-10 \%$ ) when $10 \%$ of pine wood is added, due to the low $\mathrm{k}$-value for pine wood $(\mathrm{k}=0.12 \mathrm{~W} / \mathrm{m} . \mathrm{k})$ in compare to relatively high thermal conductivity of HDPE ( $\mathrm{k}=0.5 \mathrm{~W} / \mathrm{m} . \mathrm{k})$. While, for PP-wood composites, the reduction in the $\mathrm{k}$-value by the increasing of wood content for each $10 \%$ was small (about 3-4\%) due to the fact that k-value of pure PP raw material is relatively low $(\mathrm{k}=0.2$ $\mathrm{W} / \mathrm{m} . \mathrm{k})$. Hence, the more addition of wood to the plastic means the more thermal resistance, where the thermal conductivity of the wood-plastic composites can be decreased by $25 \%$ for $30 \%$ wood content. However, the technique of WPC is useful with plastics that have relatively high $\mathrm{k}$ values (more than $0.3 \mathrm{~W} / \mathrm{m} . \mathrm{k}$ ) such as; HDPE, LDPE and PA in order to get clear benefits of wood addition, thus reasonable results. On the other hand, the increasing in the material thickness gives more thermal stability to the panels, where the k-values of thin specimens 
had fluctuated values more than that of thick specimens, beside the fact that more thickness means more thermal insulation.

Furthermore, a local simulation program called (IPPP) adopted by references [28 and 29] and based on ASHRAE relations [30] has been used to calculate the cooling load for typical single floor building in Baghdad with and without the using of Alucobond panels. The results have shown that the energy saving in the cooling load due to the use of $4 \mathrm{~mm}$ cladding Alucobond panels made of WPC core was ranged between (25-35\%). On the other hand, the energy saving due to the use of conventional $4 \mathrm{~mm}$ cladding Alucobond panels was ranged between (20$25 \%$ ), as shown in Figure 9. In both cases, the Alucobond panel is assumed to attach the walls with $5 \mathrm{~cm}$ air gap away.

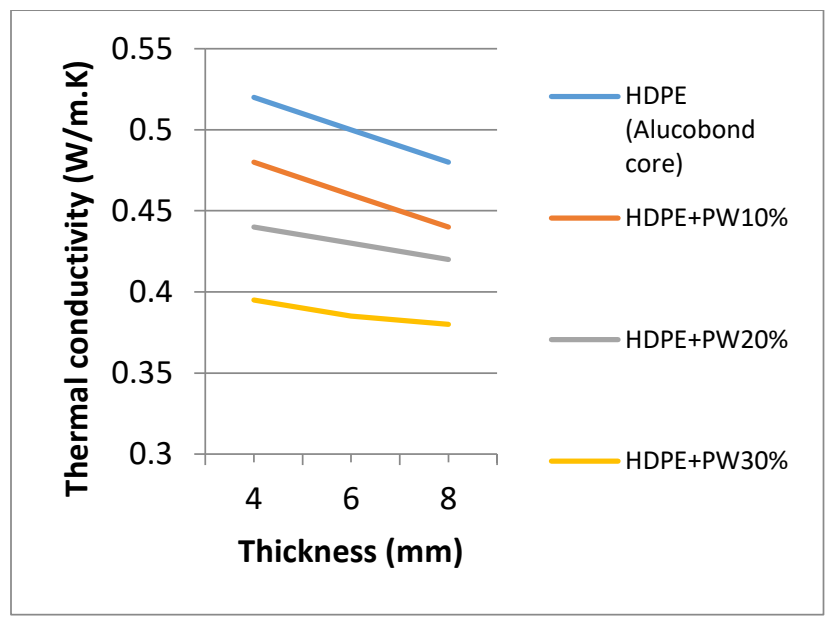

Figure 7. Variation of thermal conductivity for HDPE

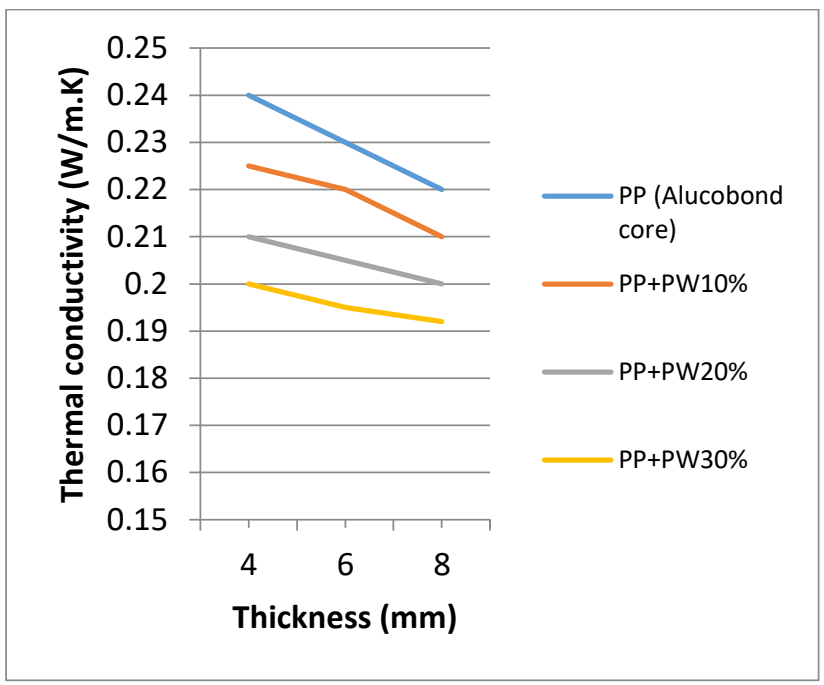

Figure 8. Variation of thermal conductivity for PP

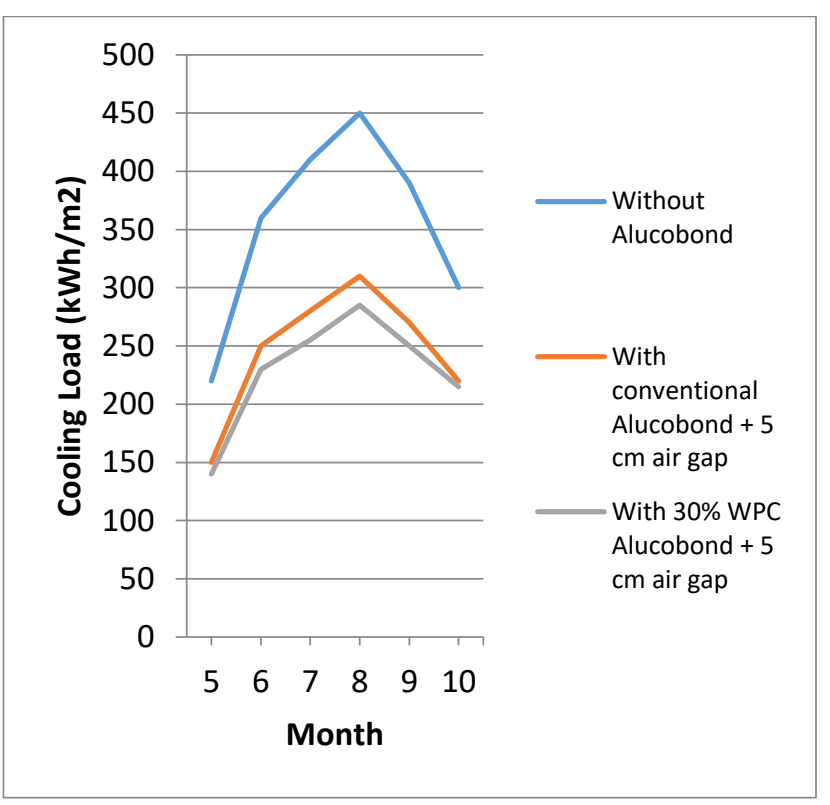

Figure 9. Comparison of cooling load for different Alucobond cases during summer

\section{Conclusions}

Wood plastic composites (WPCs) that manufactured from waste wood and recycled plastics have possessed some advantages in comparing to the conventional Alucobond panels that made of plastic materials. They are cheaper and environmentally fried. They are 
easy in manufacturing and can be produced as thermal insulation panels with a wide range of applications in the field of constructions. However, some specific points could be concluded from the recent study as following:

- The increasing in wood content leads to a decrease in $\mathrm{k}$-value for WPC material because $\mathrm{k}$-value of wood is less than that of plastic.

- The decrease in k-value of WPC was 8$10 \%$ for each $10 \%$ addition of wood.

- The energy saving due to the use of wood-plastic composites may reach up to $35 \%$ during the summer time.

Even though, that the technique of WPC is useful with plastics that have relatively high k-values such as; HDPE, LDPE and PA, but it has an effective enhancement in thermal insulation performance of Alucobond panels.

\section{Acknowledgements}

The authors would like to introduce thanks to Mustansiriyah University, college of engineering, for its support in the recent work.

\section{Conflict of interest}

The authors declare that there is no conflict of interest regarding the publication of this article

\section{References}

1. Tabarsa T., Khanjanzadeh H., Pirayesh H., "Manufacturing of wood-plastic composite from completely recycled materials", Key Engineering Materials, Vols. 471-472, Pages 62-66, 2011

2. João B., Carlos M., Fernando C., Raul F., "Influence of different thermoplastic polymer/wood ratios on the mechanical and thermal properties of composite materials", Procedia Engineering, 200, 480-486, 2017

3. John Z., Qinglin W., Ioan I., "Surface and interfacial characterization of wood-PVC composites: Thermal and dynamic mechanical properties", Wood and Fiber Science, 36(4), Pages 500-510, 2004

4. Alireza Kaboorani, "Effects of formulation design on thermal properties of wood/thermoplastic composites", Journal of Composite Materials, Vol. 44, No. 18, Pages 2205-2215, 2010

5. Song G., Qiu-yi L., Yi-wen Z., "Experimental research on the thermal insulation and flame retardancy performance of WPC wallboard made of paper-aluminum-plastics wastes", Applied Mechanics and Materials, Volumes 34-35, Pages 1676-1680, 2010

6. Diene N., Laurent M., Sandrine M., Lo1c V., Adams T., Jean-Luc G., "Thermal and mechanical properties of polypropylene/wood-flour composites", Journal of Applied Polymer Science, Vol. 119, Pages 3321-3328, 2011

7. Thanate R., Natchayapa T., Chatree H., "Mechanical and thermal properties of oil palm wood sawdust reinforced postconsumer polyethylene composites", ScienceAsia, 38, Pages 289-294, 2012

8. Yiqun F., Qingwen W., Xiaoyan B., Weihong W., Paul A., "Thermal and burning properties of wood flour poly (vinyl chloride) composite", J Therm Anal Calorim, 109:1577-1585, 2012

9. Karim B., Bernard R., Denis R., "Effect of temperature on the thermal conductivity of wood-plastic composites", Polymers \& Polymer Composites, Vol. 21, No. 7, 2013

10. Prisco U., "Thermal conductivity of flatpressed wood plastic composites at different temperatures and filler content", Sci Eng Compos Mater, 21(2), Pages 197-204, 2014 
11. Mazzanti V., Mollica F., El Kissi N., "Rheological and thermal properties of PPbased WPC", Times of polymers and composites, AIP Conference, Pages 274-277, 2014

12. Hossain M., Shoumya N., Islam M., "Effect of types of wood on the thermal conductivities of wood saw dust particle reinforced composites", 10th International Conference on Mechanical Engineering, ICME 2013, Procedia Engineering, 90, Pages $46-51,2014$

13. Rafel R., Josep P., José M., Jordi G., Francesc X., Gerard A., Pere M., "Orange wood fiber reinforced polypropylene composites: Thermal properties", Bioresources, 10(12), Pages 2156-2166, 2015 14. Patrick Z., Elke M., Andre G., Torsten T., Antje L., "Synthesis of polyamide 6/11 copolymers and their use as matrix polymer in wood-plastic composites", Journal of Applied Polymer Science, 44155, Wiley, 2016

15. Alperen K., Turker G., Seyyed H., Nadir A., "Physical, mechanical and thermal properties of wood/zeolite/plastic hybrid composites", Maderas, Ciencia y tecnología, 19(3): 339 348, 2017

16. Chung M., Park J., "An experimental study on the thermal performance of phase-change material and wood-plastic composites for building roofs", MDPI, Energies, 10 (195), 2017

17. Shirley S., Leigh M., Tim G., Adrian K., "Properties of nylon-6-based composite reinforced with coconut shell particles and empty fruit bunch fibres", Plastics, Rubber and Composites, T\&F, VOL. 47, NO. 2, Pages 77-86, 2018

18. Yong G., Shiliu Z., Yuxia C., Dagang L, "Thermal properties of wood-plastic composites with different compositions", Materials, MDPI, 12:881, 2019
19. Xingli Z., Jinglan Z., Ruihong W., "Thermal and mechanical behavior of wood plastic composites by addition of graphene nanoplatelets", MDPI, Polymers, 11, 1365, 2019

20. Henry M., A. Besnard, W. Asante, J. Eshun, S. Adu-Bredu, R. Valentini, M. Bernoux, L. Saint-Andre, "Wood density, phytomass variations within and among trees, and allometric equations in a tropical rainforest of Africa", Forest Ecology and Management, 260, Pages 1375-1388, 2010

21. The Engineering ToolBox, "Density of various wood species", accessed on 15/11/2019, available on:

https://www.engineeringtoolbox.com/wooddensity-d_40.html

22. Glass S., Zalinka L., "The wood handbook: Wood as an engineering material, Chapter 4: Moisture relations and physical properties of wood", General Technical Report, USA, 2010

23. Poletto M., Dettenborn J., Pistor V., Zeni M., Zattera A., "Materials produced from plant biomass, Part I: Evaluation of thermal stability and pyrolysis of wood", Materials Research, 13 (3), Pages 375-379, 2010

24. Poletto M., "Thermogravimetric analysis and kinetic study of pine wood pyrolysis", Brazilian Journal of Wood Science, 7(2), Pages 111-118, 2016

25. Polymer Properties Database, accessed on 19/11/2019, available on:

http://polymerdatabase.com/polymer\%20physics/ Polymer\%20Density.htm

26. Scientific Polymers, Inc., accessed on 28/11/2019, available on:

https://scientificpolymer.com/density-ofpolymers-by-density

27. The Engineering ToolBox, "Polymersphysical properties", accessed on 5/12/2019 https://www.engineeringtoolbox.com/polymerproperties-d_1222.html 
28. Tawfeeq W. M. Salih, "Theoretical and experimental study to evaluate the performance of passive house in Iraq", Ph.D. Thesis, Al-Mustansiriyah University, Iraq, 2015

29. Tawfeeq W. M. Salih, Ghanim K. Abdulsada, "Experimental and theoretical study for the performance of new local thermal insulation in Iraqi building", Renewable Energy in the Service of Mankind Vol I, 487-501, 2015

30. ASHRAE, "Chapter 27: residential cooling and heating load calculations", ASHRAE Handbook SI (Fundamentals), 1997 